\title{
BORGES-DUARTE, I. ARTE E TÉCNICA EM HEIDEGGER. Rio de Janeiro: Via Verita, 2019
}

\section{Jelson Roberto de Oliveira ${ }^{1}$}

BORGES-DUARTE, I. Arte e Técnica em Heidegger. Rio de Janeiro: Via Verita, 2019

O livro que a professora Irene Borges-Duarte acaba de publicar, sob o título (ao mesmo tempo sucinto e íntegro) Arte e técnica em Heidegger, é a versão atualizada de seu trabalho anterior, oferecido sob os dosséis do interesse do público brasileiro, com quem ela mantém intenso e fértil intercâmbio de pesquisas. Definido pela própria autora como um livro que tenta sondar o sentido que as palavras arte e técnica dizem sobre o que arte e técnica são, em si mesmas, Irene socializa o que ouviu com uma habilidade invejável, que testemunha tantos anos de dedicação caprichosa à filosofia, especialmente a heideggeriana.

Ao selecionar dois dos temas mais frequentes e instigantes do pensamento do filósofo da Floresta Negra, o livro que agora vem à luz é uma espécie de ponte. A metáfora arquitetônica traduz a intenção de aproximar duas margens, a do leitor interessado àquela outra do autor apresentado, cujas hastes de suporte são as teorias e os temas frequentes e difíceis de uma filosofia densa, como a de Heidegger. Mas não se trata de uma ponte qualquer. Antes, corresponde a uma arquitetura requintada, que revela não apenas o gosto estilístico apurado de sua autora, como também a sua maturidade filosófica, quando se trata de analisar os conceitos e acompanhar a intrincada argumentação do filósofo que busca o Ser.

\footnotetext{
${ }^{1}$ Pontifícia Universidade Católica do Paraná, Professor do Programa de Pós-Graduação em Filosofia. Coordenador do Grupo de Trabalho Filosofia da Técnica e da Tecnologia da Associação Nacional de PósGraduação em Filosofia do Brasil, Curitiba, PR - Brasil. https://orcid.org/0000-0002-2362-0494. Email: jelson.oliveira@pucpr.br.
}

https://doi.org/10.1590/0101-3173.2021.v44dossier.13.p251

\section{(6)}

This is an open-access article distributed under the terms of the Creative Commons Attribution License. 
Se é verdade, como afirma a autora, que o autor de Ser e Tempo vivia a tensão do estilo, algo que se revela principalmente no seu Beiträge zur Philosophie (obra analisada com raríssima competência, profundidade e elegância), Irene recolheu a mesma tensão, transformando-se em vigas de sustentação de sua interpretação, na qual os temas que dão título ao livro se articulam para formar o que, afinal, é próprio das pontes: levar de um lado a outro. Não por acaso, essa tarefa se revela na análise do texto que, tendo permanecido escondido, redigido entre 1936 e 1938, revelaria a concepção que transporta do tédio até surpresa. Beiträge zur Philosophie é o elo proposto por Irene Borges-Duarte como forma de compreender o tédio da modernidade, no qual o Ser já não é mais sentido e seu apelo não repercute; e aquele "segundo início", a nova surpresa aos moldes daquela vivenciada, antes, pelo mundo grego, ao qual Heidegger se volta como quem busca o susto fundamental, que tanto é um alerta diante dos entes quanto um grito em busca do Ser. Beiträge zur Philosophie é a revelaçáo dessa possibilidade e, por isso, serve de conexão entre a pergunta sobre a arte e a da técnica e, no caso do livro de Irene, entre as quase, por assim dizer, duas grandes partes de seu livro, simbolizadas pelas duas cabeças de Jano, aquele que pode recomeçar sempre. Não é por acaso que o auge do seu livro se encontra precisamente na reflexão sobre essa obra de 1936. Comparada, em ordem de importância, a Ser e o tempo, os Beiträge representam uma tentativa, segundo Irene, de tornar possível aquela linguagem nova capaz de aproximar-se do Ser. Uma linguagem que torne possível, segundo as palavras do próprio Heidegger, falar o Ser pela língua do ente, sabendo-se de antemão que o primeiro permanece silente. $\mathrm{O}$ cuidado com a nobreza da palavra, embora o cotidiano ôntico exija o seu uso comum, é o que aproxima dessa tarefa.

Heidegger, portanto, toma o que é de Nietzsche para reconhecer que a verdade do Ser se retrai e cala-se, ao mesmo tempo em que diz. Foi Nietzsche, afinal, quem nos ensinou a ler nas entrelinhas, pela via do náo dito. Como consequência, a nova linguagem (tornada objeto de uma sigética) aparece pelo não dizer que é a verdade, cujo resultado é um pensar "fundado na sintonia afetiva da 'reserva', que [se] chamará Ereignisdenken: pensar o acontecimento propício" (p. 140), que se aproxima da ideia de fundação como "apropriação mútua do ser e do seu aí enquanto pensar” (BORGES-DUARTE, 2019, p. 141). Isso é feito, obviamente, sem deixar de transpor os limites da própria filosofia e, portanto, da lógica envelhecida que aprisionava os conceitos. Nesse caso, como é impossível encontrar o pensamento fora da linguagem, é preciso inventar um novo estilo para dizer, mantendo a vocação do silêncio. Essa seria 
a única maneira de acordar o Ser que dorme no uso corrente da linguagem. Irene, com isso, traz às claras muitas respostas necessárias a qualquer um que queira se aproximar de uma filosofia tão densa e intrigante como a de Heidegger. O leitor deve a ela, por isso, suas loas.

Segundo a nossa leitura, o capítulo sexto do seu livro serve especialmente como uma espécie de eixo articulador entre o tema da arte e o tema da técnica. E é pela análise dos textos de Heidegger de 1936 que se chega à compreensão plena daquilo que será sua tese sobre a técnica e, ao mesmo tempo, paradoxalmente (embora esta palavra devesse silenciar diante da clareza argumentativa do livro) sobre a importância da arte na sua filosofia. Tudo se revela como uma espécie de filosofia em busca de um caminho para o outro pensar - na verdade, segundo a pretensão de Irene, vários caminhos intercalados e entrecruzados da ontologia hermenêutica da verdade proposta por ela, vindo a formar um "estudo sistemático" constituído por uma "sequência estrutural veraz". Reunindo admiráveis conhecimentos técnicos aliados ao domínio da língua alemã e ao poder de verter seus principais conceitos para o português, Irene associa-se aos grandes intérpretes, tanto pela profundidade do raciocínio quanto pela gentileza e elegância afetiva que sua palavra feminina transporta.

Em tal elo se revela precisamente uma reflexão sobre a essência da técnica. Para a autora, o famoso texto de Heidegger sobre o tema nada mais é do que uma espécie de crítica à superfície lisa da ação da verdade, por meio do procedimento técnico e, ao mesmo tempo, um convite a romper a tradiçáo moderna iniciada em Platáo, que vê todo conhecer e proceder humano como uma forma de dominação. Aceder à essência da técnica é, pois, colocar-se contra o comportamento técnico herdado da modernidade e, para isso, é preciso tratar a técnica não como algo dado de uma vez por todas, porém, como algo que se dispóe, como algo que está sendo. O plano de fundo dessa questão é, como é sabido, a mudança de perspectiva filosófica em direção à História do Ser, projeto inaugurado, conforme sugere Irene, precisamente com as suas Beiträge, nas quais Hedeigger expressaria seu pensamento como espécie de peça musical, em busca de novas origens. Ora, um tal projeto de um "outro pensar" teria inspiração tanto na Grécia quanto no tempo que era seu - ambas versóes de um mesmo "Ocidente": "o grego, sob a forma epocal da arte, e a sociedade tecnológica, cuja verdade se desvela apenas ao nível do pensar" (BORGES-DUARTE, 2019, p. 210). Em outras palavras, trata-se de articular as duas modalidades nas quais a história do ser acontece de maneira autêntica, pela arte e pela técnica. 
Assim, o roteiro proposto por Irene se realiza de forma integral, não apenas no desenvolvimento dos capítulos de sua obra, mas no todo de sua interpretação: os dois caminhos propostos se cruzam numa rede de entrosamento que náo descarta as diferentes abordagens, contudo, articulam e dão morada para uma compreensão elucidativa do que, do contrário, permaneceria torcido ou somente tocado superficialmente. Porque quer fugir do que ela mesma chama de derivas do seu destino na modernidade, a interpretação da arte passa por uma questão primeira sobre a questão da técnica, pela epifania da arte, a qual inclui uma análise cuidadosa e apurada das obras de Rafael, Van Gogh, Paul Klée e Eduardo Chillida, mas também de Sófocles, Rilke e Hölderlin, além de Kurasawa. Pintura, escultura, escritura e cinema seriam formas de aparição da imagem, na qual e pela qual se resgata o sentido originário do ser como tornar-se visível.

Ao reconhecer a cibernética como meio de apresentação do percurso histórico do Ser, Irene termina por levar-nos até a Grécia, para pensar o vínculo esquecido com a Arte. Seu Heidegger está em Atenas, em abril de 1962, e não esconde sua surpresa pela pura presença do Ser diante da iluminação trazida pela sombra da paisagem. Depois, em 1967, retorna à cidade para falar da proveniência da arte e a determinação do pensar. Ele pensa modos de dar um "passo atrás" e encontra-se com Atena mesma, a deusa do saber produtivo, a qual vê com antemão o que ainda não é, mas que poderá ser parte da obra. Atena é poiésis e techné, ao mesmo tempo. A deusa da Grécia simboliza a unidade primitiva entre a arte e o pensar.

O que se descobre é que, se na Grécia o homem não era mais do que um veículo do poder para qual a arte era uma manifestação (poiésis), na modernidade, ele se deteve diante do próprio poder que protagoniza como domínio sobre as demais forças da natureza, apoiado na ideia de progresso no qual o poder não é mais apenas um "estar capacitado", porém, um "fazer com que", ou seja, um forçar para que algo se comporte desta ou daquela maneira (BORGES-DUARTE, 2019, p. 212). Agora, o esquema tecnológico do mundo exige do homem uma postura de dominação. No primeiro caso, ainda estávamos no âmbito do fazer produtivo; no segundo, apenas da reprodução programada. Atena, filha de Zeus, não apenas faz, como seu pai, mas antes de fazer, tem o poder de antever, de conceber. Ela vê o que ainda está obscuro. Como sua ave, a coruja, ela consegue tirar das trevas e tornar visível o que do contrário permaneceria escuro. Esse é o símbolo do pensamento, da meditaçáo, que parte da poiésis para chegar à techné. 
Irene faz ver que, ao contrário de Atenas, agora vivemos o tempo do vazio da pura estrutura, de uma civilização marcada ciberneticamente pela intocável "autoridade anônima da ciência", segundo as palavras do próprio Heidegger (BORGES-DUARTE, 2019, p. 217). Para além de tal cenário, o filósofo pretendia buscar a origem do projeto que ocasionou a história do ser da civilização ocidental e, para tanto, buscou o que ficou impensado, aquilo que se esconde e adormece na origem. $\mathrm{O}$ começo, por isso, está um passo atrás dessa tradição filosófica que se fez técnica e mesmo da cibernética, da ciência da informaçáo e de controle que marcam a nossa época tecnológica. Heidegger quer ir para o antigo pensar, entretanto, para isso precisa de um outro pensar, de um novo pensar. A filosofia, por isso, precisa renunciar à sua linguagem técnica, própria da ciência, que também a contaminou. O filósofo pretende recuperar a habilidade meditativa e o vigor que foram sepultados pelo projeto cibernético: "no final da filosofia, mesmo esse 'outro pensar' seria, então, arte!” (BORGES-DUARTE, 2019, p. 221).

Como resultado, o que se tem é um livro coerente e até mesmo didático, embora formado por nove capítulos herdados de outras publicaçóes, agora reformados e aumentados, levando em conta a atualidade das pesquisasHeidegger e os novos interesses de sua autora. Ler esse livro, por isso, não é apenas obrigatório para quem se interessa por Heidegger ou pelas questóes que orbitam em sua obra, mas também por quem busca se aprazer com a boa filosofia, a argumentação densa moldada pela clareza gentil e pelo estilo melindroso. Irene Borges-Duarte oferece isso tudo. Saímos da travessia como quem, tendo cruzado a ponte, encheu os olhos de paisagens e, com isso, já não pensa mais por polaridades.

\section{REFERÊNCIA}

BORGES-DUARTE, I. Arte e Técnica em Heidegger. Rio de Janeiro: Via Verita, 2019

Recebido: 08/01/2021

Aceito: 15/02/2021 
OLIVEIRA, J. R. 